\title{
Pengaruh transfer of motor skill learning dari tangan sehat terhadap peningkatan fungsional tangan paresis pasien stroke subakut
}

\author{
Elina \\ Lidwina S. Sengkey \\ Program Studi Ilmu Kedokteran Fisik dan Rehabilitasi \\ Fakultas Kedokteran Universitas Sam Ratulangi Manado \\ Email: elinalie83@gmail.com
}

\begin{abstract}
This study aimed to demonstrate the effect of transfer of motor skill learning from healthy hand on increasing functional paretic's hand of stroke patient. This was a descriptive study conducted at the Instalation of Medical Rehabilitation, Prof. Dr. R. D. Kandou Hospital Manado. There were 26 patients of subacute stroke that fulfilled the inclusion criteria. All subjects were trained for 6 weeks and then were evaluated with nine hole peg test dan Sollerman hand function test. The results showed that of the 26 patients, $15(57.7 \%)$ were males. The highest percentages were as follows: mean of age was 57.58 years old (38.5\%), onset of stroke was less than 10 weeks (65.4\%), and nonhaemorrhagic stroke (88.5\%). The Wilcoxon test showed that there were significant differences of nine hole peg test and Sollerman hand function test scores before and after exercise $(P<0.001)$. Conclusion: Transfer of motor skill learning from healthy hand could increase functional paretic hand of stroke patients.
\end{abstract}

Keywords: stroke, transfer of motor skill, bilateral transfer, mirror neuron

\begin{abstract}
Abstrak: Penelitian ini bertujuan untuk membuktikan pengaruh transfer of motor skill learning tangan sehat terhadap peningkatan fungsional tangan paresis pasien stroke subakut. Jenis penelitian ini ialah deskriptif. Penelitian dilaksanakan di Instalasi Rehabilitasi Medik RSUP Prof Dr. R. D. Kandou Manado. Sebanyak 26 orang pasien stroke fase subakut yang memenuhi kriteria inklusi. Semua subyek diberi latihan selama 6 minggu kemudian dilakukan penilaian dengan nine hole peg test dan Sollerman hand function test. Hasil penelitian memperlihatkan dari 26 subjek, persentase tertinggi ialah laki-laki sebanyak 15 orang $(57,7 \%)$, usia rata-rata ialah 57,58 tahun $(38,5 \%)$, onset terjadinya stroke kurang dari 10 minggu $(65,4 \%)$, dan stroke non-hemoragik $(88,5 \%)$. Hasil uji Wilcoxon menyatakan terdapat perbedaan bermakna pada nilai nine hole peg test dan Sollerman hand function test sebelum (awal) dan sesudah (akhir) perlakuan ( $\mathrm{p}<0,001)$. Simpulan: Transfer of motor skill learning tangan yang sehat dapat meningkatkan fungsional tangan paresis pasien stroke subakut.
\end{abstract}

Kata kunci: stroke, transfer of motor skill, bilateral transfer, mirror neuron

Stroke merupakan salah satu penyebab utama disabilitas. Stroke bisa menyebabkan berbagai defisit neurologik, namun yang paling sering terganggu ialah sistem motorik. Salah satu sistem motorik yang sering terganggu yaitu paresis ektremitas atas. ${ }^{1}$ Sekitar $85 \%$ pada pasien stroke yang bertahan hidup mengalami hemiparesis, dan terdapat sekitar $55 \%-75 \%$ yang mengalami keterbatasan fungsi tangan. ${ }^{2}$ Gangguan fungsi tangan merupakan salah satu hambatan bagi pasien post-stroke untuk melakukan aktivitas sehari-hari sehingga banyak penelitian di bidang rehabilitasi yang terfokus pada penanganan perbaikan fungsi tangan setelah terserang 
stroke. ${ }^{1,3}$ Menurut World Health Organization (WHO) terdapat sekitar 15 juta orang per tahun terkena stroke. ${ }^{4}$ Prinsip teknik rehabilitasi konvensional pada pasien stroke dengan hemiparesis selalu terfokus melatih ektremitas yang paresis seperti constraint-induced movement therapy, ataupun latihan yang bersifat repetitif. Latihan-latihan ini telah terbukti memberikan perbaikan motorik yang bermakna pada pasien stroke. Akhir-akhir ini terdapat penelitian yang membuktikan bahwa terdapat peningkatan aktivitas daerah motorik otak ketika pasien-pasien stroke menonton atau memperhatikan suatu aktivitas yang berhubungan dengan fungsi tangan dalam kehidupan sehari-hari dan kemudian melakukannya. Hal ini terjadi karena adanya pengaktifan mirror neuron. ${ }^{5}$

Transfer of motor skill learning adalah proses transfer yang terjadi ketika dilakukan latihan tangan sehat pada pasien stroke. Transfer of motor skill learning melibatkan bilateral transfer dan pengaktifan mirror neuron. Bilateral transfer adalah suatu transfer kemampuan motorik dari satu tangan kepada tangan yang lain, dimana kegunaannya untuk memperbaiki fungsi ektremitas atas setelah terkena stroke. Pada awal abad 20, ditemukan adanya suatu fenomena mengenai tangan yang dilatih untuk melaksanakan suatu tugas, ternyata akan 'mengajari' tangan yang lain melaksanakan tugas yang sama. Tahun 1903, Swift meneliti tentang transfer keahlian dari tangan yang satu terhadap tangan yang lain pada pemain sulap saat melakukan juggling. ${ }^{6}$

Bilateral transfer terjadi bila terdapat atensi, motivasi, dan gerakan yang berulang. ${ }^{7}$ Bilateral transfer memberikan pengetahuan metode baru dalam bidang rehabilitasi ekstremitas atas. Metode bilateral transfer ini sesuai dengan teknik rehabilitasi ekstremitas atas yang mengikuti prinsip motor learning antara lain: 1) gerakan yang bersifat repetisi aktif; 2) sensorimotor dan proprioseptif integrasi memberikan peran penting untuk pasien post-stroke; 3) atensi tinggi dan kontrol visual ikut berperan. Berdasarkan neuro- anatomi proses bilateral transfer terjadi karena aktifitas ipsilateral dari korteks motorik yang sehat (jalur kortikospinal ipsilateral) dan jalur kortikospinal kontralateral serta terjadi transfer dari korteks motorik hemisfer sehat ke hemisfer sisi lesi melalui korpus kalosum (Gambar 1 dan 2). Selain itu, bilateral transfer juga melibatkan aktifitas mirror neuron. ${ }^{6}$

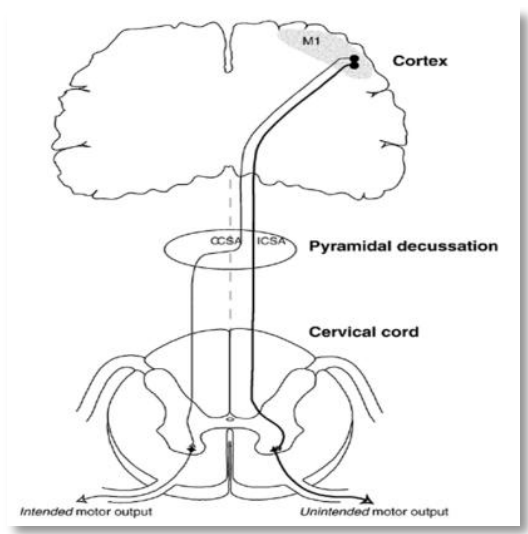

Gambar 1. Proses bilateral transfer melalui traktus kortikospinal. Korteks motorik mengirim perintah motorik melalui traktus kortikospinal baik kontralateral ataupun ipsilateral. Ket: M1: korteks motorik, ICSA = Ipsilateral corticospinal axons, CCSA $=$ Crossed corticospinal atau corticofugal

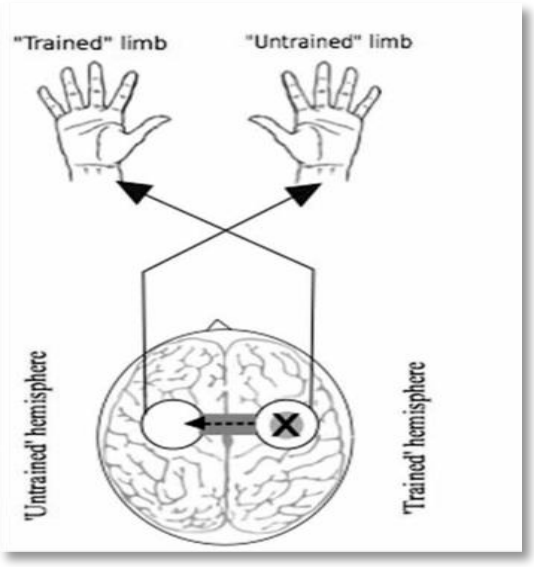

Gambar 2. Bilateral transfer di korteks motorik. Saat latihan tangan unilateral dilakukan akan terjadi transfer ke tangan yang tidak dilatih melalui korpus kalosum ke daerah korteks motorik hemisfer sebelahnya.

Mirror neuron merupakan suatu kumpulan neuron spesifik yang teraktivasi pada saat observasi maupun saat mela- 
kukan aktifitas motorik yang sama. ${ }^{7,8}$ Mirror neuron terdapat di bagian inferior parietal lobule (IPL) dan korteks premotor ventral. Mirror neuron terbagi menjadi dua kategori yaitu strictly dan broadly congruent. Strictly congruent mirror neurons meliputi $1 / 3$ keseluruhan mirror neuron, teraktifkan ketika melakukan suatu aksi yang sama, baik mengamati atau melaksanakan tugas. Broadly congruent mirror neurons merupakan 2/3 mirror neuron dan berfungsi ketika terjadi gerakan tangan yang didasari oleh logika (membawa gelas untuk diminum ke mulut) atau melakukan suatu tugas yang mempunyai tujuan. ${ }^{7}$
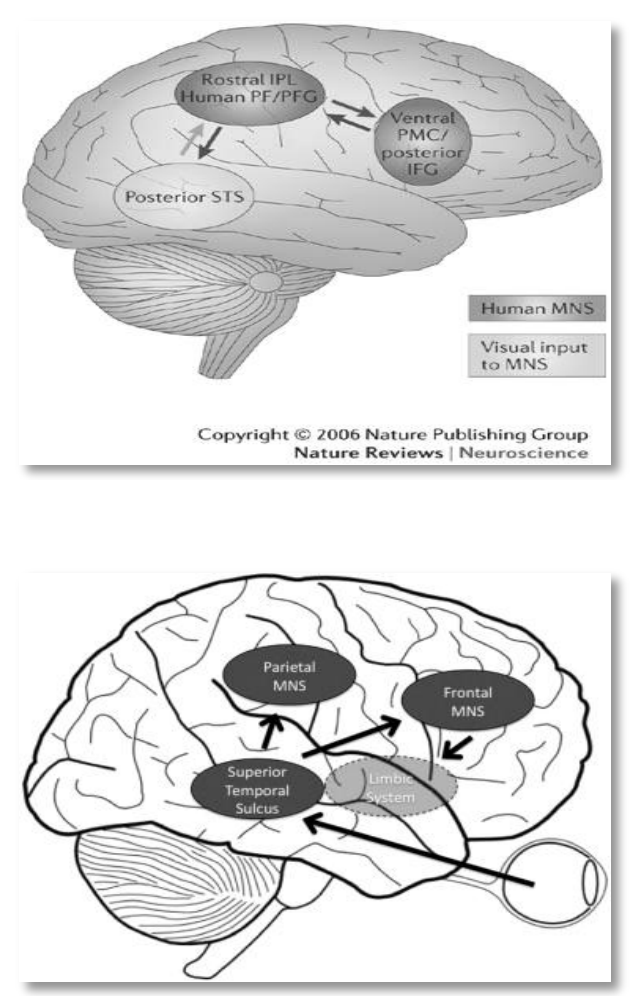

Gambar 3 dan 4. Human mirror neuron system (MNS) terdapat di daerah anterior dan posterior. MNS di anterior yaitu di inferior dari korteks frontal terdiri dari posterior inferior frontal gyrus (IFG) dan ventral premotor cortex (PMC) sedangkan di posterior yaitu bagian rostral dari inferior parietal lobule (IPL). Input visual dikirim ke posterior superior temporal sulcus (STS) yang kemudian diteruskan ke daerah MNS dan diproses di sistim limbik. Keterangan: panah hitam: penyesuaian antara informasi sensori mengenai imitasi motorik dengan deskripsi visual observasi.
Pengaktifan mirror neuron terjadi saat adanya action-observation dan objectoriented hand actions yaitu mengamati kemudian meniru aktifitas yang dilakukan oleh tangan seperti memegang, merobek dan memanipulasi suatu objek. ${ }^{7}$ Aplikasi klinis pengaktifan mirror neuron ini digunakan pada rehabilitasi pasien stroke dengan metode action-observation untuk mengembalikan fungsi motorik. ${ }^{7-9}$ Saat observasi, input visual dikirim ke posterior superior temporal sulcus (STS) kemudian diteruskan ke daerah mirror neuron dan diproses di sistim limbic yang akan mengolah informasi menjadi memori dan kemudian mengirim memori tersebut ke daerah korteks motorik. ${ }^{7}$ (Gambar 3 dan 4).

\section{METODE PENELITIAN}

Jenis penelitian ini ialah eksperimental dengan pre dan post test design. Penelitian dilakukan di Instalasi/SMF Kedokteran Fisik dan Rehabilitasi BLU RSUP Prof. Dr. R. D. Kandou Manado pada bulan Agustus sampai Oktober 2014. Subjek penelitian ini sebanyak 26 orang pasien stroke yang memenuhi kriteria inklusi. Cara pengambilan subjek dengan consecutive sampling, yaitu semua subyek yang datang dan memenuhi kriteria inklusi dimasukkan dalam penelitian sampai jumlah subyek yang diperlukan terpenuhi.

Kriteria Inklusi ialah: 1) Pasien stroke hemoragik dan nonhemoragik dengan hemiparesis serangan pertama; 2) Pasien stroke hemoragik dan nonhemoragik usia 40-80 tahun; 3) Pasien stroke hemoragik dan nonhemoragik yang sudah berlangsung antara lebih dari 2 minggu sampai kurang dari atau sama dengan 6 bulan; 4) Penglihatan normal atau jika penglihatan miopia atau presbiopia sudah terkoreksi dengan kacamata; 5) Dapat memahami dan mengikuti instruksi verbal sederhana; 6) Tidak ada gangguan kognitif (Mini Mental State Examination /MMSE $\geq 24)$; 7) Kekuatan otot bahu, lengan atas, lengan bawah, pergelangan tangan dan jari-jari tangan dari 2 sampai $4 ; 8$ ) Tidak terdapat keterbatasan lingkup gerak sendi pada 
sendi bahu, siku, pergelangan tangan dan jari-jari tangan yang paresis; dan 9) Pasien bersedia berpartisipasi dalam penelitian ini dengan menandatangani lembar persetujuan penelitian (informed consent). Kriteria eksklusi antara lain: 1) Pernah mengalami stroke sebelumnya atau multipel stroke; 2) Terdapat nyeri sendi ekstremitas atas; 3) Terdapat gangguan kognitif (MMSE kurang dari 24); 4) Terdapat spastisitas (Modified Asworth score >3); 5) Stroke hemoragik dan nonhemoragik lebih dari 6 bulan; 6) Hipertensi tak terkontrol; 7) Terdapat apraksia ideomotor, ideational/ conceptual dan limb-kinetic; dan 8) Pasien dengan hemispatial neglect.

Penelitian ini menggunakan analisis komparatif untuk membandingkan hasil pre dan post test suatu kelompok perlakuan yaitu uji T-berpasangan bila data menyebar normal atau dengan uji Wilcoxon Signed Ranks Test bila data tidak menyebar normal serta analisis komparatif untuk membandingkan dua kelompok evaluasi yaitu digunakan uji $\mathrm{T}$ - independent jika data menyebar normal atau uji MannWhitney Test jika data tidak menyebar normal.

\section{HASIL PENELITIAN}

Jumlah subyek yang memenuhi kriteria inklusi dan bersedia mengikuti penelitian ini 30 orang. Pada semua subjek dilakukan evaluasi awal pre perlakuan yaitu penilaian outcome ke-1 ialah waktu yang diperlukan untuk melakukan nine hole peg test (detik) tangan paresis serta penilaian outcome ke-2: nilai skor Sollerman tangan paresis; setelah itu diberikan latihan menggunakan tangan yang sehat dengan Nine Hole Peg Test selama 16 minggu kemudian dilakukan evaluasi akhir. Sebanyak 4 dikeluarkan dari 30 orang subyek penelitian yakni 2 orang dengan alasan tidak bisa mengikuti jadwal latihan yang ditetapkan dan 2 orang tanpa alasan yang jelas.

Berdasarkan Tabel 1 terlihat sebagian besar subjek penelitian ialah laki-laki dengan jumlah 15 orang $(57,7 \%)$.
Tabel 1. Distribusi subjek menurut jenis kelamin

\begin{tabular}{ccc}
\hline Jenis kelamin & Jumlah & Persentase \\
\hline Laki-laki & 15 & 57,7 \\
Perempuan & 11 & 42,3 \\
Total & 26 & 100 \\
\hline
\end{tabular}

Menurut Tabel 2 kelompok usia yang paling banyak yaitu usia 50-59 tahun sebanyak 10 orang $(38,5 \%)$.

Tabel 2. Distribusi subjek menurut usia

\begin{tabular}{ccc}
\hline Usia & Jumlah & Persentase \\
\hline $40-49$ & 6 & 23,1 \\
$50-59$ & 10 & 38,5 \\
$60-69$ & 6 & 23,1 \\
$70-79$ & 4 & 15,4 \\
Total & 26 & 100 \\
\hline
\end{tabular}

Berdasarkan Tabel 3 karakteristik subjek berdasarkan onset terjadinya stroke paling banyak $<10$ minggu $(65,4 \%)$. Ratarata onset stroke ialah 9,88 minggu, minimum 3 minggu dan maksimum 24 minggu.

Tabel 3. Distribusi subjek menurut waktu terjadinya atau onset stroke

\begin{tabular}{ccc}
\hline Onset & Jumlah & Persentase \\
\hline$<10$ & 17 & 65,4 \\
$10-19$ & 5 & 19,2 \\
$20-29$ & 4 & 15,4 \\
Total & 26 & 100 \\
\hline
\end{tabular}

Tabel 4 memperlihatkan rata-rata nilai MMSE yaitu 25,81 dengan nilai minimum 24 dan maksimum 28.

Tabel 4. Distribusi subjek menurut MMSE

\begin{tabular}{ccccc}
\hline $\begin{array}{c}\text { Rata- } \\
\text { rata }\end{array}$ & Median & $\begin{array}{c}\text { Simpangan } \\
\text { baku }\end{array}$ & Min & Maks \\
\hline 25,81 & 26,00 & 1,167 & 24 & 28 \\
\hline
\end{tabular}

Tabel 5 memperlihatkan bahwa subjek lebih banyak menderita paresis di sebelah 
kanan yaitu sebanyak 14 orang $(53,8 \%)$ sedangkan paresis kiri 12 orang $(46,2 \%)$.

Tabel 5. Distribusi subjek menurut sisi paresis yang diderita

\begin{tabular}{ccc}
\hline Sisi paresis & Jumlah & Persentase \\
\hline Kanan & 14 & 53,8 \\
Kiri & 12 & 46,2 \\
Total & 26 & 100 \\
\hline
\end{tabular}

Dari Tabel 6 terlihat bahwa semua subjek merupakan pengguna right handed.

Tabel 6. Distribusi subjek menurut dexterity tangan

\begin{tabular}{ccc}
\hline Dexterity tangan & Jumlah & Persentase \\
\hline $\begin{array}{c}\text { Kanan }(\text { right } \\
\text { handed })\end{array}$ & 26 & 100 \\
\hline
\end{tabular}

Tabel 7 memperlihatkan bahwa jumlah subjek stroke hemoragik sebanyak 3 orang $(11,5 \%)$ sedangkan subyek non-hemoragik 23 orang $(88,5 \%)$.
Tabel 7. Distribusi subjek menurut tipe stroke yang diderita

\begin{tabular}{ccc} 
Tipe stroke & Jumlah & Persentase \\
\hline $\begin{array}{c}\text { Stroke hemoragik } \\
\text { Stroke non- } \\
\text { hemoragik }\end{array}$ & 3 & 11,5 \\
Total & 23 & 88,5 \\
\hline
\end{tabular}

Tabel 8 memperlihatkan hasil uji Wilcoxon Signed Ranks yang menyatakan terdapat perbedaan sangat bermakna pada Nine Hole Peg test sebelum (awal) dan sesudah (akhir) perlakuan $(\mathrm{p}<0,001)$. Nilai median mengalami penurunan sesudah perlakuan dari 46,50 menjadi 25,00.

Berdasarkan Tabel 9 tidak terdapat perbedaan nilai Nine Hole Peg Test antara sisi paresis kanan dengan paresis kiri pada saat evaluasi awal atau sebelum latihan $(\mathrm{p}=0.285)$ dan evaluasi akhir atau setelah latihan $(\mathrm{p}=0,082)$.

Tabel 8. Perbandingan waktu nine hole peg test awal dan akhir evaluasi

\begin{tabular}{ccccc}
\hline Nine hole Peg test & Rata-rata & Median & Simpangan Baku & Kemaknaan \\
\hline Awal & 57,88 & 46,50 & 29,658 & \\
Akhir & 30,12 & 25,00 & 16,108 & $\mathrm{p}<0,001^{* *}$
\end{tabular}

Keterangan **: uji Wilcoxon

Tabel 9. Pengujian perbedaan nilai nine hole peg test sisi paresis kanan dengan paresis kiri.

\begin{tabular}{|c|c|c|c|c|c|}
\hline Nine Hole Peg test & Paresis & Rata-rata & Median & Simpangan Baku & Kemaknaan \\
\hline \multirow[t]{2}{*}{ Awal } & Kanan & 63,14 & 53,50 & 37,484 & \multirow[b]{2}{*}{$\mathrm{p}=0.285^{*}$} \\
\hline & Kiri & 51,75 & 45,50 & 16,198 & \\
\hline \multirow[t]{2}{*}{ Akhir } & Kanan & 34,21 & 30,00 & 19,423 & \multirow[t]{2}{*}{$\mathrm{p}=0.082^{* *}$} \\
\hline & Kiri & 25,33 & 22,00 & 9,875 & \\
\hline
\end{tabular}

Keterangan *: uji Mann-Whitney Test , ${ }^{* * *}$ uji T independent

Tabel 10. Perbandingan nilai Sollerman hand function test awal dan akhir evaluasi

\begin{tabular}{ccccc}
\hline Sollerman Hand Function test & Rata-rata & Median & Simpangan Baku & Kemaknaan \\
\hline Awal & 53,23 & 58,00 & 10,405 & \\
Akhir & 78,38 & 80,00 & 2,772 & \multirow{2}{*}{$<0,001^{* * *}$}
\end{tabular}


Tabel 11. Pengujian perbedaan nilai Sollerman hand function test sisi paresis kanan dengan paresis kiri.

\begin{tabular}{cccccc}
\hline Sollerman Hand Function Test & Paresis & Rata-rata & Median & Simpangan Baku & Kemaknaan \\
\hline Awal & Kanan & 50,21 & 53,00 & 11,807 & \\
\cline { 2 - 6 } & Kiri & 56,75 & 59,00 & 7,497 & \\
& & & & & \\
\hline Akhir & Kanan & 77,86 & 79,50 & 3,207 & \\
\cline { 2 - 5 } & Kiri & 79,00 & 80,00 & 2,132 & \\
\hline
\end{tabular}

Keterangan **: uji Mann-Whitney Test

Tabel 10 memperlihatkan hasil uji Wilcoxon yang menyatakan bahwa ada perbedaan sangat bermakna pada nilai Sollerman hand function test sebelum (awal) dan sesudah (akhir) perlakuan (p $<0,001)$. Nilai median mengalami peningkatan dari 58,00 menjadi 80,00.

Hasil uji Mann-Whitney di Tabel 11 menyatakan bahwa tidak ada perbedaan nilai Sollerman hand function test antara sisi paresis kanan dengan paresis kiri saat awal evaluasi atau sebelum dilakukan latihan $(\mathrm{p}=0,157)$ dan saat akhir evaluasi atau setelah latihan $(\mathrm{p}=0,108)$.

\section{BAHASAN}

Berdasarkan perhitungan karakteristik subjek penelitian didapatkan distribusi berdasarkan jenis kelamin (Tabel 1) lakilaki sebanyak 15 orang $(57,7 \%)$. Hal ini sesuai dengan kepustakaan yang menyatakan stroke lebih sering terjadi pada lakilaki. ${ }^{10-12}$ Pada penelitian ini, jumlah subjek lebih banyak laki-laki kemungkinan karena meningkatnya faktor risiko pada laki-laki seperti merokok, hipertensi, dan hiperlipidemia.

Karakteristik subjek berdasarkan onset terjadinya stroke paling banyak $<10$ minggu $(65,4 \%)$. Pada penelitian ini digunakan subjek yang menderita stroke fase subakut yaitu pasien stroke yang sudah berlangsung antara lebih dari 2 minggu sampai kurang dari atau sama dengan 6 bulan. Menurut kepustakaan, stroke pada fase akut (saat terjadi stroke sampai 2 minggu) masih terdapat keadaan hemodinamik dan neurologik yang belum stabil, edema otak, dan jaringan nekrotik yang belum terabsorpsi. Stroke fase subakut (3 minggu sampai 6 bulan) merupakan fase paling penting oleh karena pada saat ini terjadi absorpsi dan resolusi edema serta jaringan rusak, dan mulai terjadi reorganisasi saraf sedangkan fase kronis stroke ditandai dengan selesainya reorganisasi sistem saraf (lebih dari 6 bulan). ${ }^{13-15}$ Hal ini menjadi alasan mengapa pada penelitian ini dipilih subjek stroke subakut.

Subjek pada penelitian ini lebih banyak menderita paresis disebelah kanan yaitu sebanyak 14 orang $(53,8 \%)$. Hal ini mungkin secara kebetulan subjek yang memenuhi kriteria inklusi lebih banyak stroke paresis kanan. Meskipun demikian karakteristik subjek ini sama dengan penelitian Ausenda dimana subjek penelitian tersebut juga lebih banyak pasien dengan hemiparesis kanan.,16,17 Jumlah subjek stroke hemoragik sebanyak 3 orang $(11,5 \%)$ sedangkan non-hemoragik 23 orang $(88,5 \%)$. Hal ini sesuai dengan penelitian Ausenda ${ }^{1}$ dimana subjeknya juga lebih banyak pasien stroke hemoragik yaitu sebanyak 32 orang sedangkan non- hemoragik sebanyak 2 orang. Menurut kepustakaan dikatakan juga pasien stroke nonhemoragik biasanya lebih banyak sekitar $85 \%$ dibandingkan pasien stroke hemoragik yaitu $15 \% .^{18-20}$

\section{SIMPULAN}

Berdasarkan hasil pengujian dan bahasan dapat disimpulkan bahwa terdapat pengaruh transfer of motor skill learning dari latihan tangan sehat sehingga dapat meningkatkan fungsional tangan paresis yang dinilai dengan meningkatnya skor 
Sollerman Hand function test dan berkurangnya waktu untuk melakukan Nine Hole Peg test.

\section{DAFTAR PUSTAKA}

1. Ausenda CD, Carnovali M. Transfer of motor skill learning from the healthy hand to the paretic hand in stroke patients: a randomized controlled trial. Eur J Phys Rehabil Med. 2011;47:41725.

2. Yavuzer G, Selles R, Sezer N, Sutbeyaz S, Bussmann JB, Koseoglu F, et al. Mirror therapy improves hand function in subacute stroke: a randomized controlled trial. Arch Phys Med Rehabil. 2008;89:393-98.

3. Iosa M, Morone G, Ragaglini MR, Fusco A, Paolucci S. Motor strategies and bilateral transfer in sensorimotor learning of patients with subacute stroke and healthy subjects. A randomized controlled trial. Eur J Phys Rehabil Med. 2012;48:1-9.

4. Morris JH, Wijck FV, Joice S, Ogston SA, Cole I, MacWalter RS. A comparison of bilateral and unilateral training in early poststroke rehabilitation: A randomized controlled trial. Arch Phys Med Rehabil. 2008;89:1237-45.

5. Data statistik kunjungan penderita di Instalasi Rehabilitasi Medik BLU RSUP Prof. Dr. R. D. Kandou Manado, 2009.

6. Iosa M, Morone G, Ragaglini MR, Fusco A, Paolucci S. Motor strategies and bilateral transfer in sensorimotor learning of patients with subacute stroke and healthy subjects. A randomized controlled trial. Eur J Phys Rehabil Med. 2012;48:1-9.

7. Iacoboni M, Mazziota JC. Mirror neuron system: Basic findings and clinical applications. Ann Neurol. 2007; 62:213-8.

8. Oztop E, Kawato M, Arbib MA. Mirror neurons: Functions, mechanisms and models. Neuroscience letters. 2013;540:43-55

9. Destro MF, Rizzolatti G. Mirror neurons and mirror systems in monkeys and humans. Physiology. 2008;23:171-9.

10. Sollerman C, Ejeskar A. Sollerman hand function test. Scand J Plast Reconstr Hand Surg. 2005;29:167-76.

11. Brogard C, Vestling M, Sjolund BH. Shortened constraint-induced movement therapy in subacute stroke-No effect of using a restraint: a randomized controlled study with independent observers. J Rehabil Med. 2009;41: 231-6.

12. Eapen RP, Parikh JH, Patel NT. A study of clinical profile and risk factors of cerebrovascular stroke. Gujarat Medical Journal. 2009;64:47-54.

13. Kamal A, Aslam S, Khattak S. Frequency of risk factors in stroke patients admitted to DHQ Teaching Hospital D.I Khan. Gomal Journal of Medical Sciences. 2010;8:200-3.

14. Richards CL, Dauphinee SW, Malouin F. Outcome measurement: Basic principles and application in stroke rehabilitation. In: Selzern ME, Clarke S, Cohen LG, editors. Textbook of Neural Repair and Rehabilitation vol II. USA: Cambridge University Press, 2000; p. 16-7.

15. Byrd R, Gibson M, Gleason MH. Bilateral transfer across ages 7 to 17 years. Percept Mot Skills. 2006;62:87-90.

16. Kumar S, Mandal MK. Bilateral transfer of skill in left and right handers. Laterality. 2005;10:337-44

17. Chase C, Seidler R. Degree affects intermanual transfer of skill learning. Exp Brain Res. 2008;190:317-28.

18. Stinear CM, Barber PA, Coxon JP, Fleming MK, Byblow WD. Priming the motor system enhances the effects of upper limb therapy in chronic stroke. Brain. 2008;131:1381-90.

19. Taub E. Harnessing brain plasticity through behavioral techniques to produce new treatment in neurorehabilitation. American psychologist. 2004;59:692-704.

20. Sunderland A, Tuke A. Neuroplasticity, learning and recovery after stroke: A critical evaluation of constraint-induced therapy. Neuropsychological rehabilitation. $2005 ; 15(2): 81-96$. 